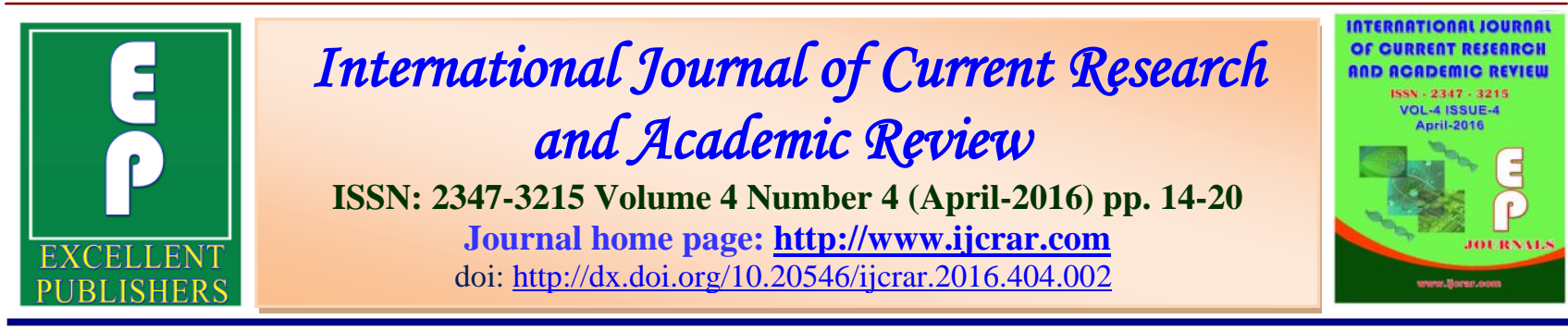

\title{
Diagnostic Study on the Contamination in Operations Theatres in the Hospitals of Kirkuk City, Iraq
}

Noor Alrifaai ${ }^{1^{*}}$ and Ibraheem Al Jebory ${ }^{2}$

Microbiology department,college of scieince/ Kirkuk university, Iraq

*Corresponding author

\section{KEYWORDS}

Operation

Theatre,

Nosocomial

Infection,

Surgical Site

Infection,

Microbial

Contamination,

Bacterial Isolates.

\section{A B S T R A C T}

A total of (222) samples were collected from different locations of the operation theatres during the period 1st of November 2014 to 30th of June 2015 from Kirkuk general hospital of Kirkuk city to determine the degree of contamination present in operation theatres and to evaluate the resistance of these isolated microbes to some antibiotics, after culturing these samples and incubation, (96) sample (43\%) showed microbial growth, the identification using biochemical tests showed (55) sample (57\%) were gram negative bacilli and (41) sample (42\%) were gram positive cocci, the results showed that Staphylococcus epidermidis was the most common isolated bacteria with (21) isolate (21.8\%), followed by S.aureus (20) isolate (20.8\%), Ps.aeruginosa(14) isolate(14.5\%), E.coli (12) isolate (12.5\%), K.pneumoniae (7) isolates (7.2\%) and P.mirabilis which constituted (7) isolates (7.2\%), and P.vulgaris (6) isolates (6.2\%), K.oxytoca (3) isolates(3.1\%), (3) isolates Enterobacter cloacae (3\%), Pseudomonas flourescence (2) isolates(2\%), serratia. marcescens (1) isolate(1\%), the Antibiotic susceptibility test was done for (82) bacterial isolates including (S.epidermidis, K.pneumoniae S.aureus, P.mirabilis, Ps.aeruginosa, E.coli ) By considering them the most commen causes of nosocomial infections isolated in this study and these isolates were tested for (11) different antibiotics including (Ampicillin,Amoxicillin, Ceftazidime,Gentamicin, Amikacin, Teteracycline, Nalidixic acid, Chloramphenicol,Tobramycine, Cefixime, Nitrofurantoin).

\section{Introduction}

Contamination of operating theatres is one of the most life-threatening sources of nosocomial infection for patients, especially in transplant surgery, heart surgery, cystoscopy and transurethral resection of prostate and bladder tumours (Madsen, 1985). Many sources have been reported to be responsible for the contamination of operation theatres including antiseptic solutions, ventilation systems and unfiltered 
air which spread the microbes on the equipments and personnel move back and forth between the operating theatres and other parts of the hospital without changing gowns or slippers (Emmerson, 1998). The most important bacteria that can contaminate surfaces and tools of operations theatres could be a Normal flora that coexist naturally in the mouth, skin and respiratory tract which are mostly non-pathogenic in normal conditions but become a source of infection in surgical interventions (Shehadeh, 2003) to evaluate and determine the type and number of different types of bacteria present in the halls of hospitals, particularly sensitive units such as surgical operations theatres is a large concern and importance globally, it was found that $10 \%$ of the infections that infect patients were an infections acquired by them while their staying in the hospital and this infection may Have serious consequences in terms of increasing infection rates between patients and the length of their stay in the hospital and thereby increase the mortality rate (Manual \& Klibber,1998).

\section{Materials and Methods}

\section{Specimens Collection}

(222) swabs were taken from 4 operating theatres in kirkuk general hospital which includes: general surgery, urologic surgery, neuro surgery, deliveries surgery, by using cotton-tipped swabs the samples were collected from the surfaces, equipment and antiseptic solutions, before and after operations.

To check the sterility of articles and surfaces in the major Operation theatres in the hospital, a sterile cotton swab moistened with sterile normal saline used to collect the samples. All samples were labeled properly and then, the swab was put into test tubes containing $5 \mathrm{ml}$ sterile brain-heart broth and mixed properly as to discharge its contents. The samples were taken to the lab and cultured on blood and MacConkey agar petri dishes then placed in the incubator for 24 hours at a temperature of $37^{\circ} \mathrm{c}$.

\section{Identification}

After incubation a single colony of each sample has been taken to conduct the purification process by streaking on the plates of agar so as to isolate a pure single colonies for the purpose of diagnosis and then planted on Slant agar and stored in the refrigerator to use it for the tests (Alfred, 2007).

The initial diagnosis was done based on morphological characteristics of the growing colonies on MacConkey Agar and Blood agar, which include the size of the colonies, color and convexity, texture and smell as well as cultural characteristics including production of dyes and lactose fermentation and blood hemolysis and the type of hemolysing (Cruicksinak et al., 1975), a microscopic examination then was done by preparing a gram stain slide to observe the way cells gathered and their shape and the capability to be stained to classify and differentiate them (Cowan, 2006).

The biochemical tests included a number of tests (oxidase, catalase, indole, urease, methyl red voges Proskauer test, triple sugar iron agar, simmon citrate) was done to confirm the diagnosis of bacteria to genuses and species.

\section{Antibiotic Susceptibility Test}

The Antibiotic Susceptibility Test was done by (Kirby - Bauer Disc Diffusion method) A sterile cotton swab was used to streak the surface of Mueller Hinton agar plates. (11) different antibiotics made of Filter paper 
disks containing designated amount of the antimicrobial drugs obtained from commercial supply firms (bioanalysis, Turkish) were used. The Mueller Hinton agar plates were allowed to dry before applying antibiotic disc. Then antibiotic discs were gently placed on the agar plates, which were then left at room temperature for 1 hour to allow the diffusion of the antibiotics into agar medium. The plates were then incubated at $37^{\circ} \mathrm{C}$ for 24 hours. If an antimicrobial activity was present on the plates, it was indicated by an inhibition zone. After the end of the incubation period the diameters of inhibition zones around the antibiotic disks on the agar recorded and the results were compared with standard specifications, as stated (CLSI M100, 2007).

\section{Results and Discussion}

During the 6 month period, a total of 222 samples were taken from the operations theatres of general hospital in kirkuk city and processed for culturing and sensitivity test. A total of 96 different organisms were isolated from 222 samples thus culturing positivity was $43.2 \%$, as shown in Table1.Staphylococcus.epidermidis accounted the most common organism. Followed by Staphylococcus aureus (20.8\%). accounted 2nd most common organism. Many studies Proven that Staphylococcus epidermidis owning many virulence factors that contribute to resist the bacteria body's defenses and antibiotics, disinfectants, including possession of a capsule and the slime layer. as (Mack, 1999) mentioned that some isolates of Staphylococcus epidermidis have the ability to produce the Slime layer that will help the adhesion to the surfaces of medical alternatives, this is because this bacteria considered to be normal flora of the body, but they have the ability to be pathogenics at appropriate conditions.
Pseudomonas aeruginosa counted as $3^{\text {rd }}$ common organism $(14.5 \%)$, this bacteria is an opportunistic pathogen that can be found in most moist environments and has a combination of features such as the ability to survive and spread in hospital environments, acquisition of multiple virulence factors and intrinsic resistance to commonly used antibiotics and disinfectants. This makes $P S$. aeruginosa a major life threating agent that is responsible for many outbreaks in operating theatres. Followed by Proteus spp. (13.5\%), Escherichia coli(12.5\%) which considered to be The first major causative agent of surgical wounds infections (Kheder, 2002), the other organisms isolated were Klebsiella pneumoniae (7.2\%). Klebsiella oxytoca(3.1\%). Entrobacter cloacae (3.1 $\%)$. Pseudomonas flourescence (2\%) Serratia marcescens (1\%).

The samples were collected from (13) different places including (Floor, Walls, Windows, lighting device, Anesthesia device, Mask of Anesthesia, operation table, surgical tools table, beds, sinks, disinfectants and antiseptics, hands and Lab coat of medical staff) and the results showed that the floor and the sinks were the most contaminated place in the operation theatre (93\%),this findings agreed with (Abbas, 2012) who has reported that the floor in the operating theatres is the most contaminated place, Where it was observed in some operation theatres that some members of the medical staff are coming out of operation rooms with their sterile protective boots to the passages of the hospital that have already been passed by the patients and their visitors with their own boots, leading to contamination of the shoe and therefore the floor of the operations room when he returns with the same contaminated shoe which increases the spread of germs and spread it in various places operations long. surgical tools table is the third most contaminated 


\section{Int.J.Curr.Res.Aca.Rev.2016; 4(4): 14-20}

place $(73 \%)$ which may be due to the incorrect sterilization way and, as the use of random concentrations of disinfectants and sterilizers cause increased bacterial resistance to them (Aldoav, 1993). The contamination of these locations due to moist conditions which is a favorable environment for most bacteria especially gram negative bacilli (Jawetz et al., 2007) the other places graduated with different contamination percentages (figure 1).

Table.1 Bacterial Species Isolated from Surgical Operation Theatres

\begin{tabular}{|c|l|c|c|}
\hline $\begin{array}{c}\text { Serial } \\
\text { number }\end{array}$ & \multicolumn{1}{|c|}{ Name of organism } & $\begin{array}{c}\text { Number of } \\
\text { organism } \\
(\mathrm{n}=96)\end{array}$ & $\begin{array}{c}\text { Percentage of } \\
\text { total } \\
\text { Organisms }\end{array}$ \\
\hline 1 & Staphylococcus epidermidis & 21 & $21.8 \%$ \\
\hline 2 & Staphylococcus aureus & 20 & $20.8 \%$ \\
\hline 3 & Pseudomonas aeruginosa & 14 & $14.5 \%$ \\
\hline 4 & Proteus spp & 13 & $13.5 \%$ \\
\hline 5 & Escherichia coli & 12 & $12.5 \%$ \\
\hline 6 & Klebsiella pneumoniae & 7 & $7.2 \%$ \\
\hline 7 & Klebsiella oxytoca & 3 & $3.1 \%$ \\
\hline 8 & Enterobacter cloacae & 3 & $3.1 \%$ \\
\hline 9 & Pseudomonas flourescence & 2 & $2 \%$ \\
\hline 10 & Serratia marcescens & 1 & $1 \%$ \\
\hline & total & 96 & $100 \%$ \\
\hline
\end{tabular}

Figure.1 Bacterial Incidence in the Operation Theatres Locations

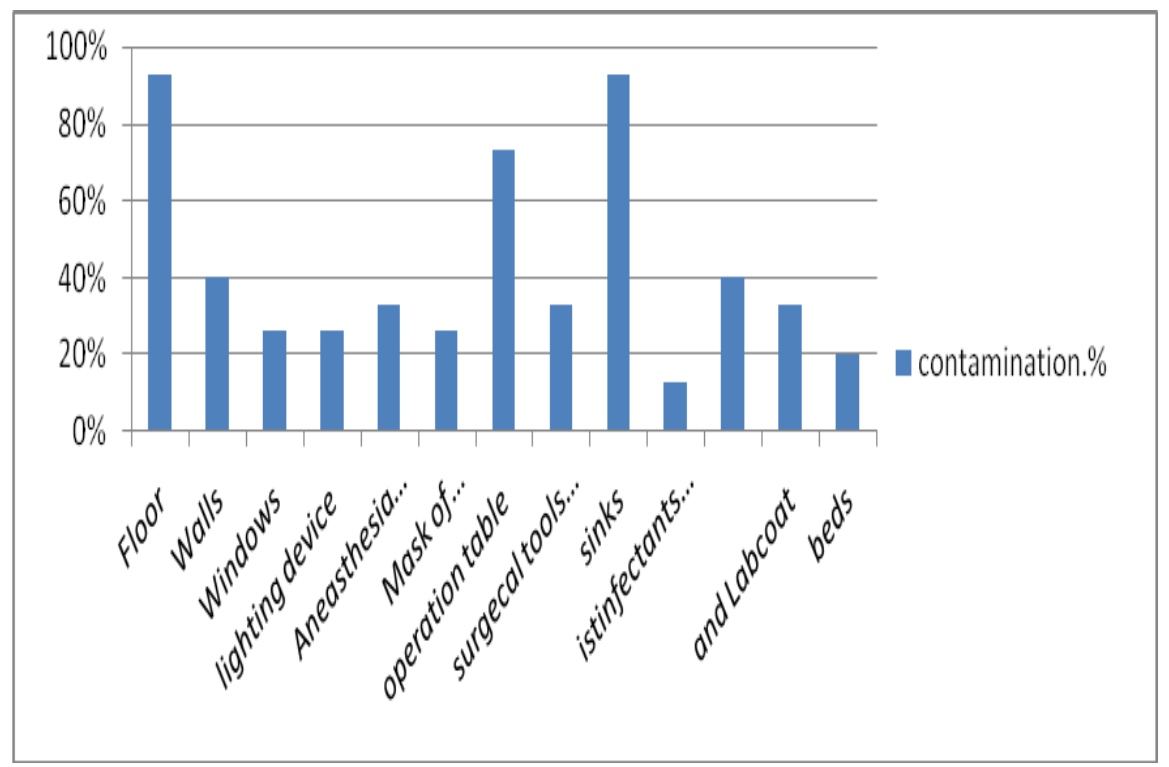


Figure.2 Bacterial Resistance to Antibiotics

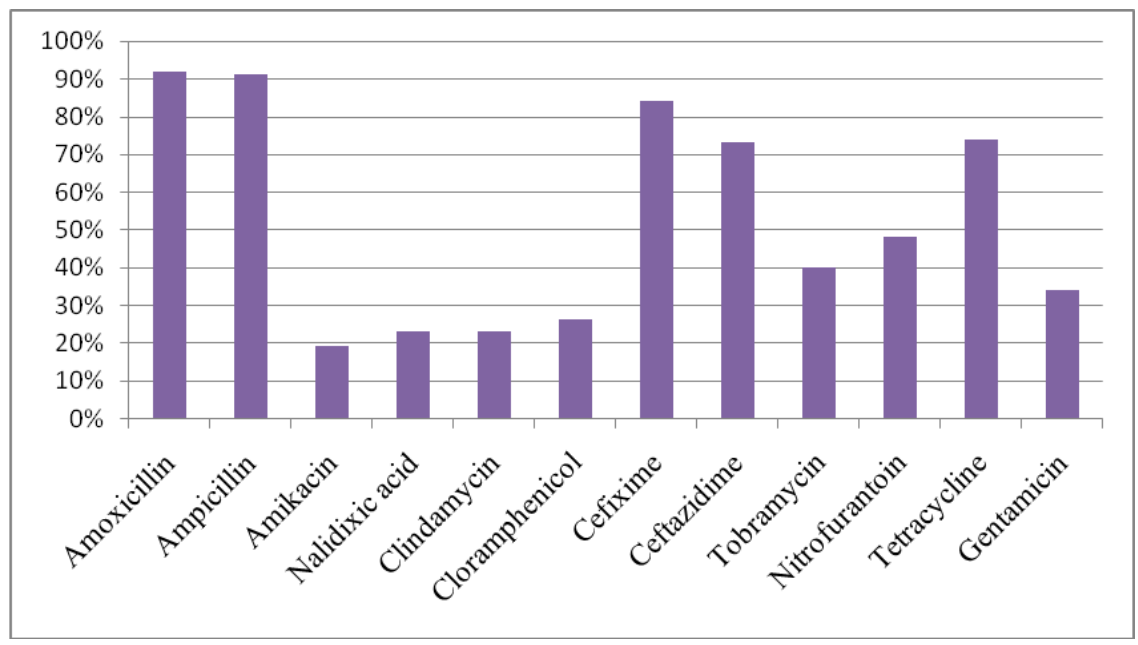

This may indicate that sterilization methods are not efficient in our operating theatres and are putting patients at a risk of postoperative infections. the results showed that all Bacterial isolates had a different resistance for the antibiotics as shown in the figure-2 the test results showed high rate of resistance among gram positive and negative bacterial isolates species and that there is a clear divergence in the impact of antibiotics on the different types of bacteria even within one bacterial species, as isolates exhibited high resistance to $\beta$-lactam antibiotics, which include penicillins such as Ampicillin and Amoxicillin, as many studies have shown that many of the bacterial species showed high resistance to $\beta$-lactam antibiotics and that resistance return to several reasons, the most common is to produce enzymes ( $\beta$ - Lactamase ), which encodes by a genes on chromosome or plasmid (Forbes et al., 2002), which works to destroy the $\beta$-lactam ring of penicillins or cephalosporins antibiotics and turn it into inactive complex, the resistance also result from the ability of bacteria to change the permeability of cell membrane that contains the Porins, as antibiotics enter the bacterial cell by diffusing in these Porins Therefore, mutations in the genes encoded for porines generate resistance to these antibiotics (Mimes et al., 1993), as well as bacterial resistance may occur by changing the goal site that antibiotics are working on. The study results showed also a high rate of resistance to Cefexime and Ceftazidime antibiotics wich belongs to the cephalosporins as these antibiotics work to inhibit manufacturing process of bacterial cell wall through the overlapping with manufacturing process of peptidoglycan layer, and perhaps the reasons for this resistance back to the bacterial excretion of $\beta$-lactamase enzymes who works on inactivating $\beta$-lactams antibiotics by breaking the $\beta$-lactam effective ring of penicillins and cephalosporins (Anderwes $e t$ al., 2002), while the bacterial resistance to aminoglycosides antibiotics, which include (Gentamicin, Amikacin, Teteracycline) happen by three mechanisms are: modulating antibiotic molecule by modified enzymes or the incidence of mutations, such as chromosomal mutations in the gene encoded for the target protein in the Sub unit S30 of the bacterial ribosome, causing the loss of anti familiarity to link the target protein and reduce the permeability of the bacterial cell antibiotc (Levinson and Jawetz, 2004). 
Int.J.Curr.Res.Aca.Rev.2016; 4(4): 14-20

While the resistance to Tetracycline was (74\%), the cause of the bacterial resistance to Teteracyclines a result from the loss of the bacterial outer membrane proteins which reduces the permeability of the antibiotic to inside of the bacteria (Katzung, 2001), or by having bacterial stream systems, as well as the production of modified enzymesand the change in the target location of the antibiotic (Murray et al., 1999)

As for Nalidixic acid the bacterial resistant was $(23 \%)$, and $(34 \%)$ were resistant the Chloramphenicol, the cause of bacterial resistance to Chloramphenicol is result from modifying the antibiotic molecule by Chloramphenicol acetyl transferase enzyme encoded by gene on bacterial plasmid which loses antibiotic effectiveness (Fluit et al., 2001).

\section{References}

Abbas, Ali Taher. 2012. Bacteriological study of Bacterial contaminants in intensive care unit in Al-Nasiryia city.

Aldoav, Hend Mohsen. 1993. The effect of chemical disinfectants on bacteria in contaminated operations theatres. Master Thesis, Faculty of Science, University of Baghdad.

Alfred, E.B. $2007 . \quad$ Benson's microbiological applications in laborator general microbiology. $10^{\text {th }}$ ed. McGraw - Hill companies. New York.

Andrews, S.J., Brooks, P.T., Hanbury, D. 2002. Ultrasonography and abdominal radiography versus intravenous urography in investigation of urinary tract infection in men : Prospective incident cohort study. BMJ, 324-454.

Clinical and Laboratory Standard Institute (CLSI). 2007. Performance standards for Antimicrobial Susceptibility testing, seventeenth Informational supplement. Vol. 27. No. 1. Pennsylvania.USA.

Cowan, M.K., Talaro, K.P. 2006. Microbiology A systems approach. 1st ed. McGraw - Hill companies, Inc.

Cruickshank, R., Duguid, J.P., Morrnion, B.P., Swain, R.H.A. 1975. Medical Microbiology. $20^{\text {th }}$ ed. Vol. 1, Churchill Livingstone. London.

Emmerson, M.A. 1998. A microbiologist's view of factor contributing to infection. New horizons Baltmore: Vol. (6): pp 3-10.

Fluit, A.C., Visser, M.R., Schmitz, F.J. 2001. Molecular detection of antimicrobial resistance. Clin. Microbiol. Rev., 14(4): 836-71.

Forbes, B.E., Sahm, D.F., Weissfad, A.S. 2002. Diagnostic Microbiology $11^{\text {th }}$ ed. Moisby, USA.

Jawetz, E., Melnick, J.L., Adelberg, E.A. 2007. Medical microbiology. 24 th ed.The Mcgrawhill companies.

Katzung, B.G. 2001. Basic and Clinical Pharmacology. $8^{\text {th }}$ ed. Lange Medical Books. McGraw-Hill.

Kheder, A.K. 2002. Studies on antibiotic resistance by plasmids of Pseudomonas aeruginosa. Ph.D. Thesis, College of Education, University of Salahadin, Erbil- Iraq.

Levinson, W., Jawetz, E. 2004. Medical microbiology and immunology examination and board review. $8^{\text {th }}$ ed. Lange medical books, McGraw-Hill. New York.

Mack, D. 1999. Molecular mechanisms of Staphylococcus epidermidis biofilm formation, J. Hosp. Infect., 43: (suppl) 113-125.

Madsen, P.O., Larsen, E.H., Dorflinger, T. 1985. Infectious complications after instrumentation of urinary tract. Urol., 26(1): 1517. 


\section{Int.J.Curr.Res.Aca.Rev.2016; 4(4): 14-20}

Manual, R.J., Klibber, C.C. 1998 .The epidemiology and prevention of invasive aspergillosis. J. Hospital Infect., 39: 95-109.

Mims, C., Play Fair, J., Roitt, I., Wakelin, D., Williams, R., Anderson, R.M. 1993. Medical Microbiology. $1^{\text {st }}$ ed. Year Book Europe limited. Mosby Company. USA.
Murray, P.R., Baron, E.J., Pfaller, M.A., Tenover, F.C., Yolken, R.H. 1999. Manual of Clinical Microbiology. (7th) ed. American Society of Microbiology. Washington, U.S.A. Shehadeh, S. 2003. Infection control. Dental Medium, 11(1): 6-7.

\section{How to cite this article:}

Noor Alrifaai and Ibraheem Al Jebory. 2016. Diagnostic Study on the Contamination in Operations Theatres in the Hospitals of Kirkuk City, Iraq. Int.J.Curr.Res.Aca.Rev.4(4): 14-20. doi: http://dx.doi.org/10.20546/ijcrar.2016.404.002 